\title{
Imagen, linaje y discurso en la fachada de San Esteban de Salamanca
}

\author{
Image, lineage and speech on the façade of San Esteban de Salamanca
}

\author{
Juan Pablo Rojas Bustamante ${ }^{1}$ \\ Doctorando en Historia del Arte \\ Universidad de Salamanca
}

Resumen: En este texto se dibuja el contexto de materialización de la fachada de San Esteban de Salamanca, teniendo en cuenta la complejidad del siglo XVI en el caso de la trayectoria de la Orden de Predicadores en la ciudad universitaria, los nexos con Carlos $V$ y la cultura visual de las élites del momento. En el hastial se emplean las mismas estrategias elegidas para ensalzar la figura del Emperador en cuanto a su mítico y noble origen, aplicadas al promotor, fray Juan Álvarez de Toledo. Se analiza la proyección visual de los Dominicos a partir de los diferentes discursos del éxito y poder de la Orden.

Palabras clave: Fachada, Orden de Predicadores, Reforma, escultura, Carlos V, Juan Álvarez de Toledo, discursos visuales, linaje, estudios visuales, San Esteban de Salamanca.

Abstract: In this paper the context of materialisation of the façade of San Esteban de Salamanca is drawn, considering the complexity of the sixteenth century in the case of the trajectory of the Order of Preachers in the university city, the links with Carlos $\mathrm{V}$ and the culture visual of the elites of the moment. In the gable end, the same strategies chosen are used to extol the figure of the Emperor in terms of his mythical and noble origin, applied to the promoter, Fray Juan Álvarez de Toledo. The visual projection of the Dominicans is analysed from the different discourses of success and power of the Order.

Key Words: Façade, Order of Preachers, Reform, sculpture, Carlos V, Juan Álvarez de Toledo, visual discourses, lineage, visual studies, San Esteban de Salamanca.

\footnotetext{
1 (iD) https://orcid.org/0000-0002-9554-6748 jprboz@usal.es

(C) 2019 Philostrato. Revista de Historia y Arte
} 
I panorama cultural que tuvo lugar en la Europa de Carlos $V$ alcanzó un profuso desarrollo, en donde las formas $y$ planteamientos humanistas se impusieron en diversos monumentos. Este es el caso del hastial exterior de la iglesia de San Esteban de Salamanca (Fig. 1). Se propone el estudio de las imágenes ejecutadas entre 1524 y 1540 para desentrañar sus significados. El linaje del comitente, Fr. Juan Álvarez de Toledo, que se exhibe como poderosa marquesina, se complementa con una serie de figuras profanas que se insertan en el edificio religioso. Se analiza el entramado visual de la portada de la iglesia dominica sin perder de vista la fachada de la Universidad de Salamanca, dos encargos ejecutados coetáneamente. En un segundo momento, acotado entre 1610 y 1623, se terminan de poner las esculturas concluyendo la imagen exterior oeste de la iglesia. Partimos de los estudios históricos e iconográficos previos sobre el tema sumados a otras corrientes de investigación en donde se pretende ampliar la perspectiva desde la intervisualidad y los estudios visuales, siguiendo las enseñanzas y líneas de estudio de la profesora Lucía Lahoz ${ }^{2}$.

En un trabajo anterior, esbozamos algunos de los puntos de conexión de las imágenes de la fachada de San Esteban con la Reforma de los Dominicos y con la Universidad de Salamanca, además de los vínculos de la familia del promotor con Carlos $\mathrm{V}^{3}$. Se ha tomado como punto de partida la interpretación del hastial de Paulette Gabaudan y Luis Cortés, quienes explican que una obra como esta tiene que instruir y edificar, y que lo cumple desde dos vertientes básicas: exaltar la Orden de Predicadores y dar a conocer la familia del donante. Concluyen que el primer cuerpo está dedicado a los fundadores, el segundo a la Iglesia militante y el cuerpo alto al Pontificado, con el mismo esquema de la puerta de la Universidad salmantina ${ }^{4}$.

En la fachada de la iglesia quedan consignados los aspectos fundamentales que la Orden quiso proyectar en su vinculación de poder con la nobleza y la monarquía de la mano del promotor, con una rica cultura visual de conocer de primera mano los panoramas de ciudades como Toledo, Valladolid, Salamanca y París. Su formación y entorno familiar se caracterizaron por el amplio cultivo intelectual propiciado por su padre, Fadrique Álvarez de Toledo, II Duque de Alba, quien aparece representado en el friso del primer cuerpo como un digno caballero completado por su escudo en el que se resumen

\footnotetext{
${ }^{2}$ Agradezco las explicaciones y aportes de la Dra. Lucía Lahoz, sin los que el presente artículo no habría podido elaborarse.

${ }^{3}$ Juan Pablo Rojas Bustamante, "Fray Juan Álvarez de Toledo y el programa humanista de la fachada de la iglesia de San Esteban de Salamanca" en Humanistas, helenistas y hebraístas en la Europa de Carlos $V$, coord. Miguel Anxo Pena González e Inmaculada Delgado Jara, (Salamanca: Servicio de Publicaciones, Universidad Pontificia de Salamanca, 2019), pp. 381-409.

${ }^{4}$ Luis Cortés Vázquez y Paulette Gabaudan, La fachada de San Esteban, (Salamanca: Ediciones de la Diputación de Salamanca, 1995), pp. 100-103.
} 


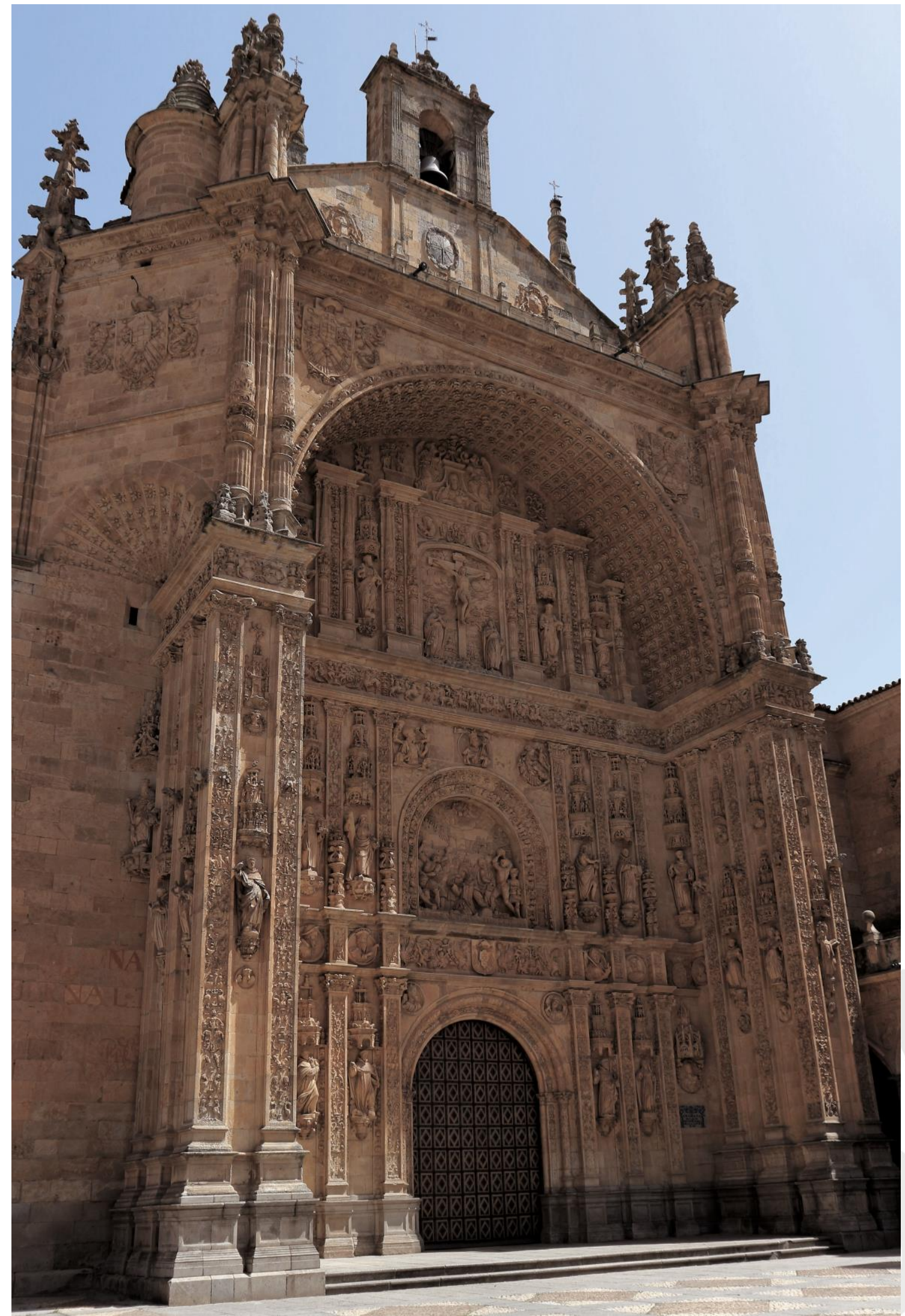

Fig. 1. Fray Juan Álvarez de Toledo (ideólogo programa iconográfico), Fachada de la iglesia de San Esteban, 15241623, Salamanca (Foto autor(C) 
sus victorias militares y políticas, como indican el número de banderillas y el Toisón de Oro otorgado por Carlos V en 1519. Fray Juan como mediador y vía de transferencia cultural imprimió en la portada la idea de consolidación del convento de San Esteban como centro de ejemplaridad dominica tras un difícil proceso reformativo, además de los nexos con Carlos $\mathrm{V}$, a quien no habían apoyado todos los frailes. Con la Reforma y la complicada situación durante la Guerra de las Comunidades se trazó posteriormente un planteamiento visual que limpiaba la imagen de la Congregación, y que no dejaba lugar a dudas de la postura dominica y su relación con los demás poderes y autoridades.

\section{Entre la tradición tardogótica y el Barroco}

En el siglo XVI en España, como defendió Fernando Marías, coexistieron dos prácticas entre los principios medievales y la corriente renacentista ${ }^{5}$. Se percibe ese bilingüismo estilístico sobre todo en el interior del templo, y en el planteamiento de la imagen exterior, en la que se consigue una armoniosa unidad que abarca la usanza tardogótica, las primeras formas renacientes y finalmente la retórica barroca.

El hastial se concibe a modo de portada monumental estructurada como un retablo de piedra, cuyas estatuas se ubican en peanas con sus doseletes al estilo bajomedieval como se ve en las figuras de bulto redondo del retablo mayor de la Catedral de Toledo, en las fachadas góticas francesas o en la misma catedral nueva de Salamanca. En San Esteban se proyecta según la tradición medieval pero traducida a un lenguaje renacentista. Se puede aplicar la teoría de Michael Camille sobre la manera de incorporar una figura de bulto redondo a la escenografía de todo el templo:

"el arco apuntado y [...] el doselete, implicaban seguridad. Al proporcionar un sitio exacto, un lugar que observar, funcionaba de alguna manera como el marco en la pintura moderna. Más importante aún, permitía a los espectadores colocarse con relación a la representación. Muy raramente en la escultura gótica encontramos figuras aisladas sin un dosel encima, excepto por lo que respecta a las gárgolas [...]. La envoltura del arco, por tanto, no sólo contiene y protege a la figura, sino que, independientemente de su estilo más cercano a la vida real, la eleva dentro de un orden eclesiástico eterno"6.

La enmarcación espacial de las esculturas en la arquitectura forma parte del todo, en donde el dosel y pedestal confirman la vinculación al lugar sagrado, además de cumplir una función profiláctica. En el caso de San Esteban, se disponen casi a modo de sagrario, pues los doseletes platerescos evocan la parte superior de una custodia o relicario. La relación de estos con

\footnotetext{
${ }^{5}$ Fernando Marías, El siglo XVI: Gótico y Renacimiento, (Madrid: Sílex, 1992), pp. 17-50.

${ }^{6}$ Michael Camille, Arte gótico. Visiones gloriosas, (Madrid: Akal, 2005), p. 38.
} 
las piezas de orfebrería y ajuar litúrgico parece evidente, englobando el conjunto en la misma órbita semántica visual hilada por la propia liturgia y predicación. El mismo término de "tabernáculo" -recogido en la documentación del pleito entre los herederos de Fr. Juan, los condes de Teba, y el convento de San Esteban para continuar con las obras, publicado por Enrique Valdivieso7- se empleaba a partir del Gótico para referirse al sagrario ubicado en un altar.

Ya apuntaba Manuel Gómez Moreno sobre la fachada trazada por Juan de Álava que "todo encaja en lugar propio y con valor adecuado a su función; las imágenes señorean, como es justo, sobre las líneas arquitecturales, que parecen sólo destinadas a guarnecerlas, y altas chambranas, de invención suya y directamente inspiradas en lo gótico, las cobijan". Termina diciendo que "De gótico no hay más que dos chambranas o doseletes, correspondientes a unas medallas en el primer cuerpo"8. Se refiere a los medallones de la primera pareja bíblica. Adán se presenta como un hombre maduro con los huesos notoriamente salidos, en antítesis con su pareja, Eva, quien aparece como imagen de deseo, joven y con los pechos remarcados con la técnica de paños mojados que evocan la imagen de la lujuria, pues de esta manera se transmite la lascivia en un juego visual de fantasías en el que se condena el pecado despertándolo. En el interior del tambor del cimborrio se repiten Adán y Eva, esta vez desnudos y complementados con sendas cartelas sobre la expulsión del Paraíso. La idea del pecado original, expulsión del Edén y sus consecuencias son palpables en el exterior, a plena vista de los espectadores. Los cambios producidos inherentemente como consecuencia del paso del tiempo aparecen subrayados en sus doseletes, pues son los únicos de estilo "moderno" y no "a la romana", por lo que no solo se les dignifica con las formas góticas, que requerían de mayor trabajo y dedicación, sino que marcan esta diferencia. Este aspecto se repite en las formas arquitectónicas, dando como resultado una imagen políglota de la iglesia de San Esteban, con total armonía.

Se aúnan los gustos e imágenes del siglo XVI que terminan por configurar esa estética de formas clásicas en sintonía con los monumentos patrocinados y dedicados a Carlos V. Otro ejemplo se ve en el interior de la nave de la iglesia, en donde se disponen las esculturas de la Anunciación, María en el lado del Evangelio y san Gabriel en el de la Epístola, entre las penúltimas capillas laterales, en vez de en la última como era costumbre al anteceder el crucero. Ambas repiten las formas de las repisas y de los doseletes del exterior. Su ubicación se puede entender por el empleo de la

\footnotetext{
7 Enrique Valdivieso González, "Una planta de Juan de Álava para la iglesia de San Esteban de Salamanca", Boletín del Seminario de Estudios de Arte y Arqueología: BSAA, 40-41, (1975), pp. 228-238.

8 Manuel Gómez Moreno, Catálogo monumental de España. Provincia de Salamanca, Tomo I, (Madrid: Ministerio de Educación y Ciencia, Dirección General de Bellas Artes, Servicio Nacional de Información Artística, 1967), p. 253.
} 


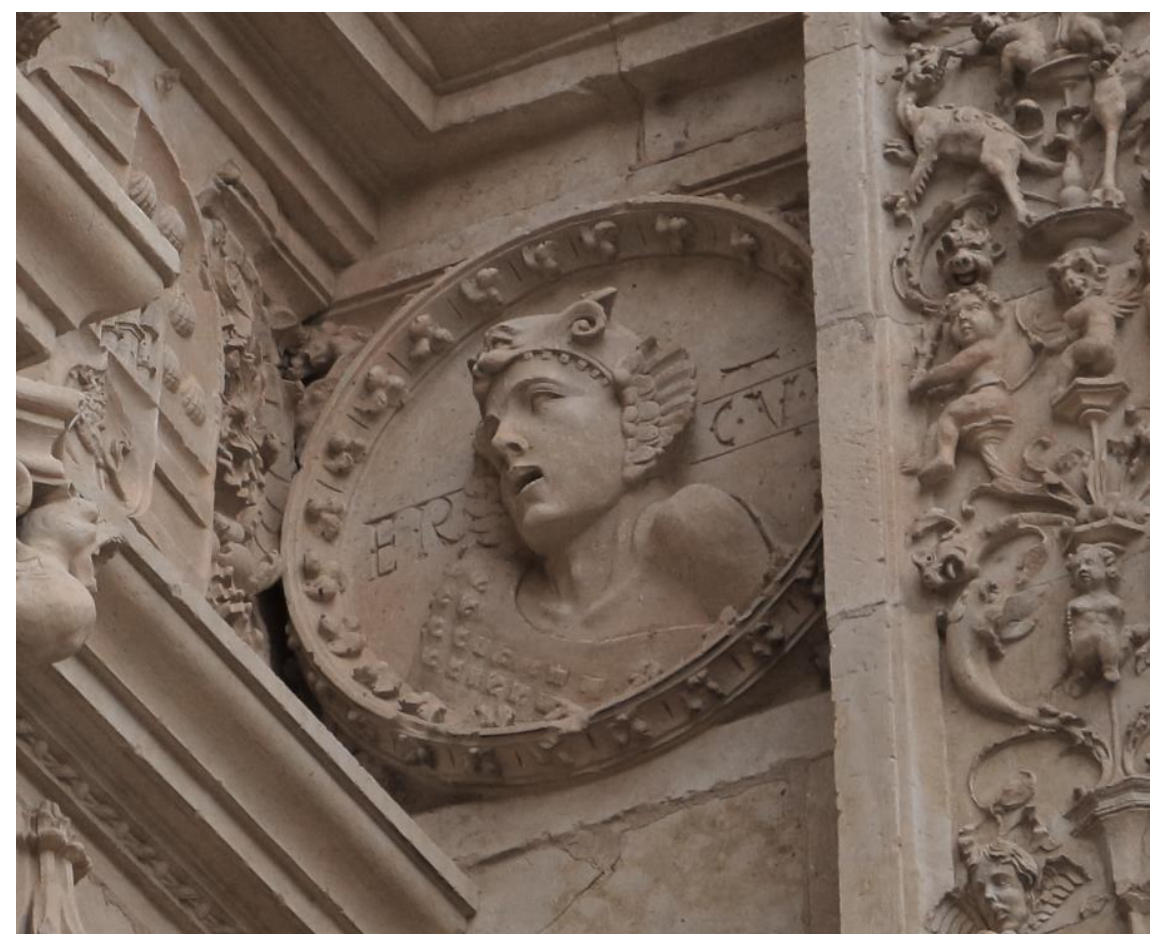

Fig. 2. Anónimo, Hércules, ca. 1524-1540. Portada de la iglesia de San Esteban, Salamanca. (Foto autor@)

iglesia hasta la línea del crucero, que entonces estaba tapiada y que funcionaba como cabecera, por lo que las esculturas antecederían el testero como era costumbre. Indicaba Alfonso Rodríguez G. de Ceballos que "El cuerpo de la iglesia se concluyó antes de la partida para Roma del cardenal obispo de Burgos, a saber, hacia 1540. Hay constancia de que se levantó entonces un tabique provisional de ladrillo entre la nave y el transepto, delante del cual se fabricó un altar de prestado donde el Cardenal celebró la primera misa solemne que se dijo en el nuevo templo"9. Y en donde José Luis Espinel resalta que se llevaron a cabo algunas sesiones del Capítulo General de 1551, en el que se definieron aspectos importantes de las provincias dominicas de América ${ }^{10}$.

\section{El Emperador como modelo de la Casa de Alba}

La Casa Ducal de Alba desempeñó funciones de suma importancia en pro del establecimiento de Carlos en España, continuando su apoyo a la monarquía que tantos beneficios le había traído desde que Enrique IV de Castilla le otorgara a García Álvarez de Toledo el título de duque de Alba en 1472. En la plástica, las retóricas visuales con las que se difundió e impuso

\footnotetext{
9 Alfonso Rodríguez G. de Ceballos, La iglesia y el convento de San Esteban de Salamanca. Estudio documentado de su construcción, (Salamanca: Centro de Estudios Salmantinos, 1987), p. 29.

10 José Luis Espinel Marcos, San Esteban de Salamanca. Historia y guía, siglos XIII-XX, (Salamanca: Editorial San Esteban, 1978), p. 132.
} 


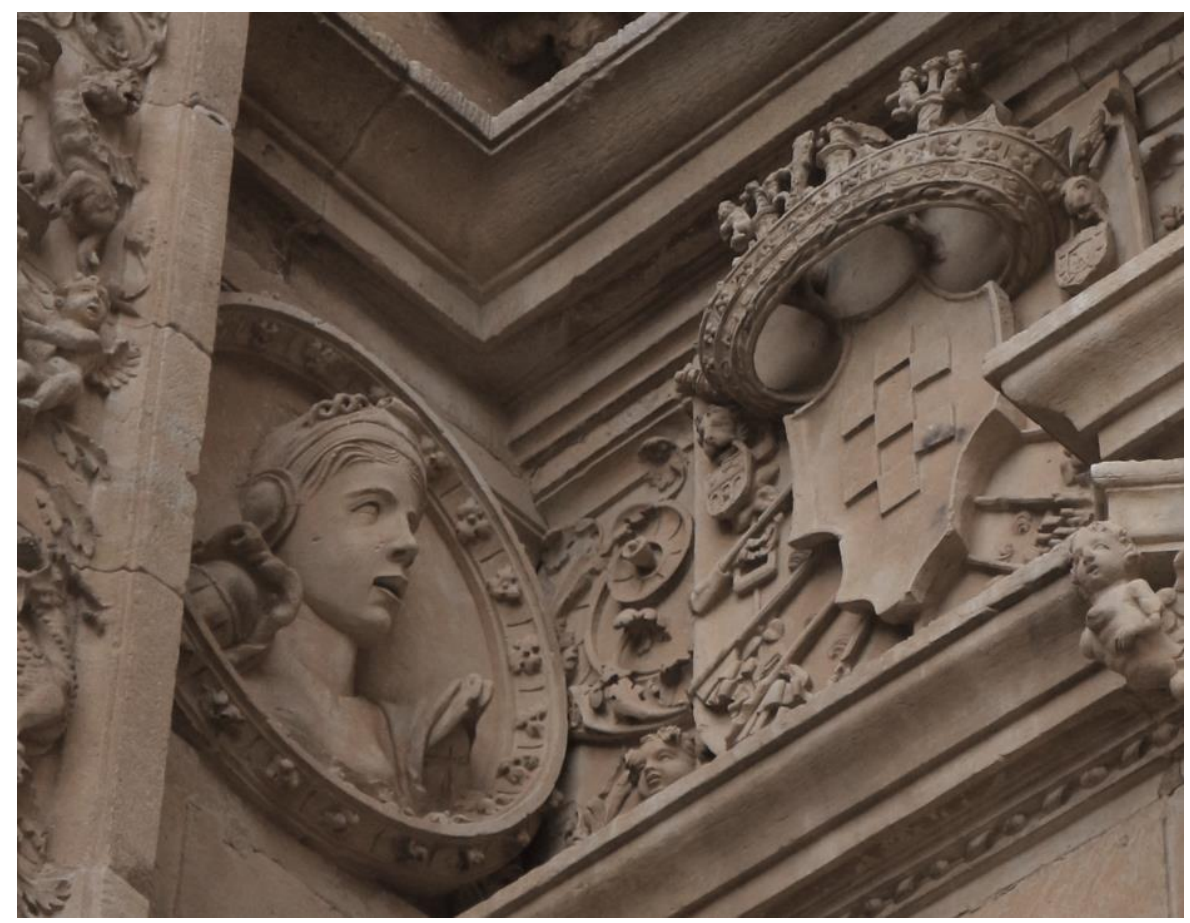

Fig. 3. Anónimo, Hebe, ca. 1524-1540. Portada de la iglesia de Esteban, Salamanca. (Foto autor@)

la imagen de Carlos $\mathrm{V}$ se modelaron entre la tradición del caballero medieval y la figura del príncipe renacentista, como teorizó Fernando Checa desentrañando su influencia en la política y en la plástica del siglo XVI como héroe mítico ${ }^{11}$.

En San Esteban, destaca el trabajado medallón de Hércules en la fachada (Fig. 2), único personaje con inscripción identificativa que disipaba cualquier duda sobre el vínculo mítico de fray Juan con el héroe clásico. La galería de personajes clásicos se completa con Hebe (Fig. 3), los tondos laterales en los machones, entre los que se reconoce a Escipión o la Sibila (Fig. 4), las figuras sobre los estribos del cimborrio y con los medallones en las enjutas de los arcos del nivel superior del claustro de Procesiones. En el claustro convergen varios niveles visuales proyectados hacia la liturgia pública y cotidianidad conventual, al recorrer el espacio, los fieles asistían a la petrificación clara de la historia de la infancia de Cristo, los profetas que anunciaron su llegada y en las puertas laterales los personajes ilustres de la Orden de Predicadores, sumado al reformador Gregorio Magno, destacándose la intervisualidad establecida entre el exterior e interior del conjunto. Desde el claustro de Procesiones, se ven los dos trabajos de Hércules que culminan los estribos del cimborrio, campo visual de figuras renacentistas y mitológicas. Este patio fue terminado por fray Martín de Santiago en 1544, fecha indicada en una pequeña cartela de piedra en el nivel superior de uno de los capiteles de los

${ }^{11}$ Fernando Checa Cremades, Carlos V y la imagen del héroe en el Renacimiento, (Madrid: Taurus, 1987). 
arcos de la crujía norte. La atmósfera clasicista se inserta decisivamente en el establecimiento del nuevo claustro que ocupa el lugar del anterior, y que desempeñó importantes funciones, tanto para las procesiones con el pueblo como para espacio de tránsito para los novicios, que tenían una puerta que daba al sobreclaustro ${ }^{12}$. También sobresale el Capítulo Viejo en la panda oriental, que funcionó como espacio de enterramiento y reunión de los frailes desde el siglo XIV hasta $1634^{13}$. Para la difusión de los Studia Humanitatis en España, Martin Biersack expone cómo el alto clero se interesó por la cultura clásica y los estudios humanísticos, leyeron a los clásicos y conocieron a la perfección los mitos, sobre todo durante el último cuarto del siglo XV ${ }^{14}$.

Durante el reinado de Carlos $\mathrm{V}$, la proliferación de universidades marcó una etapa de poder como fuerte institución, en la que los altos cargos políticos y eclesiásticos llevaban las riendas. Las fundaciones universitarias de La Española, Lima y México constituyeron tres focos de poder administrativo, cultural y político del Emperador, las dos primeras de la mano de los Predicadores. Pero no solo se promovieron las instalaciones de nuevos centros, sino que, como planteó Inmaculada Arias, el poder gubernamental fortaleció las existentes, como las de Salamanca, Valladolid y Alcalá, con un control regio gestionado a partir de visitas ${ }^{15}$. El orden establecido, de una u otra forma, obligó a las demás instituciones a someterse, y la Orden de Predicadores no sería la excepción. Los Dominicos se interesaron por la instauración de centros de estudios en América y en el caso de San Esteban de la mano de los Álvarez de Toledo, participando del triunfo del monarca y uniéndose a su carro triunfal como se refleja en su fachada occidental. El conocimiento como agente de poder funcionó efectivamente en la expansión dominica por el mundo, y como se refleja en aquellas fundaciones en América en las que el objetivo principal no era la evangelización, los focos académicos, en un principio conventuales, adquirieron cada vez mayor fuerza hasta consolidar muchas de las grandes universidades actuales.

Los dirigentes trabajaron en el mismo eje de control y difusión, como se explica al estudiar la vinculación entre el Ducado de Alba y la monarquía. Así, personalidades como Fr. Juan Álvarez no solo servían en la esfera religiosa, sino al poder laico, como era usual desde el siglo XIV en los altos cargos de la Iglesia, y que Miguel Anxo Pena deja constancia al analizar la relación entre

\footnotetext{
12 Justo Cuervo, Historiadores del Convento de San Esteban de Salamanca, Tomo I, (Salamanca: Imprenta católica salmanticense, 1914), p. 361.

${ }^{13}$ Espinel Marcos, San Esteban de..., p. 213.

14 Martin Biersack, "El Humanismo italiano en Castilla: vías y centros de difusión en el siglo XV", en Humanistas, helenistas, Actas, p. 45.

${ }^{15}$ Inmaculada Arias de Saavedra Alías, "Las universidades hispánicas durante el reinado de Carlos V", en Carlos V y la quiebra del humanismo político en Europa (1530-1558): Congreso internacional, Madrid 3-6 de julio de 2000, coord. José Martínez Millán, (Madrid: Sociedad Estatal para la Conmemoración de los Centenarios de Felipe II y Carlos V, 2001), pp. 383-395.
} 

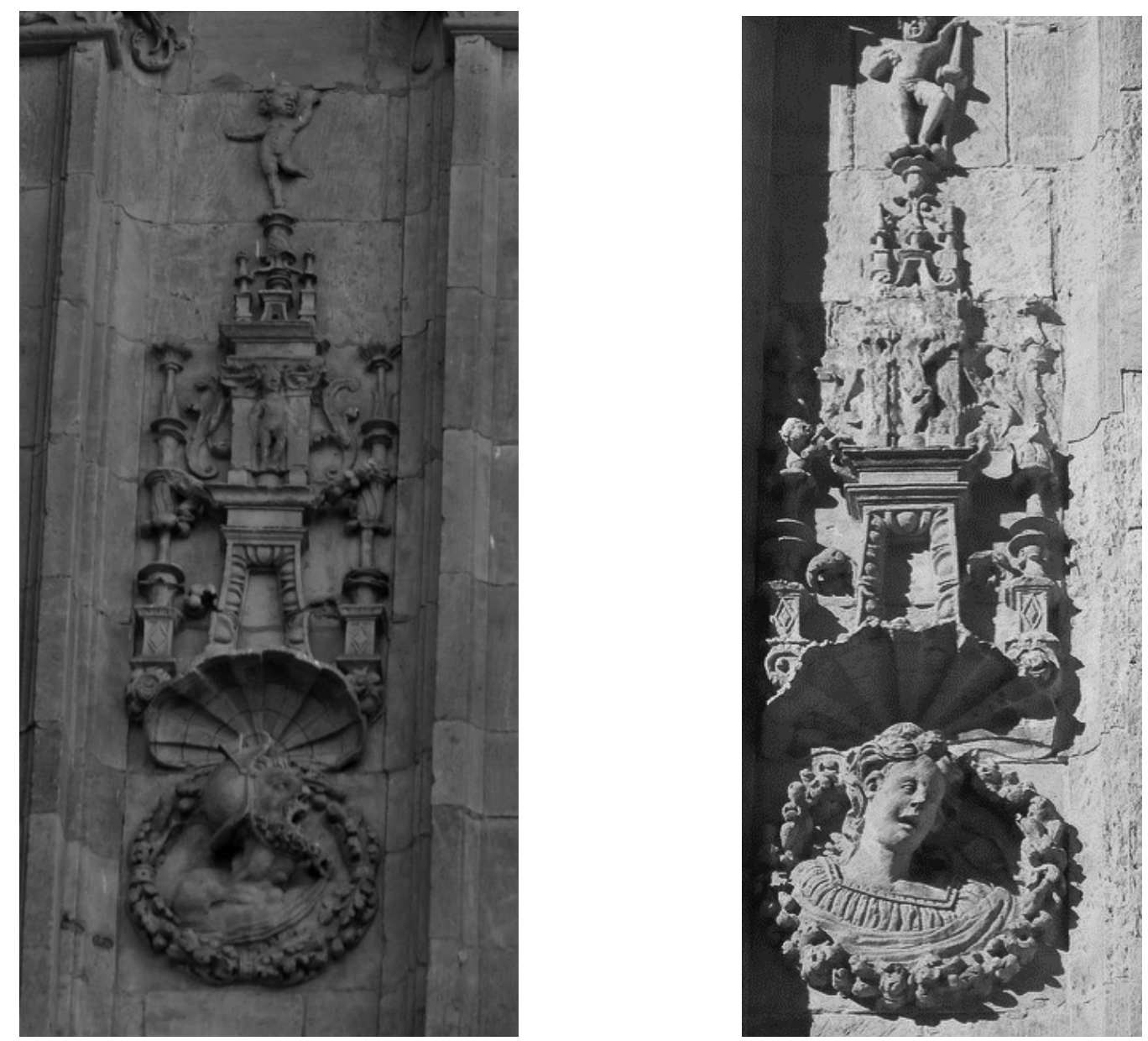

Fig. 4. Anónimo, Escipión y La Sibila, ca.1524-1540. Detalle de la fachada de la iglesia de San Sebastián. Salamanca. (Foto autor@)

las Órdenes Mendicantes y las universidades ${ }^{16}$. En este caso se entiende bien con el control regio en el Papado a través del Cardenal dominico, y en la figura Real como espejo de la nobleza.

\section{Linajes en piedra}

Como se ha dicho antes, la relación entre los Dominicos y el Emperador se refleja también en la confección de las imágenes, pues se emplean los mismos recursos en la fachada y cimborrio de San Esteban para subrayar la importancia del linaje del promotor. Por este motivo y por la proximidad de San Esteban con la Universidad, conviene estudiar el aspecto de la puerta universitaria como modelo y competencia directa. Las formas y frisos con putti, unicornios y decoraciones a candelieri evidencian el gusto por una

16 Miguel Anxo Pena González, "Dominicos y Franciscanos en las universidades medievales", en La Universidad de Salamanca y el pontificado en la Edad Media, coord. Miguel Anxo Pena González y Luis Enrique Rodríguez-San Pedro Bezares, (Salamanca: Universidad Pontificia de Salamanca, 2014), p. 140. 
estética pionera en Salamanca. Los frailes proyectaron a escala superior y en gran altura el proyecto de conjunto presentado por la fachada de los pies de la iglesia en el que, al igual que en la Universidad, funciona como árbol genealógico. Así como en la puerta del Estudio los Reyes Católicos sirven de base para Carlos V y el Pontificado, en San Esteban, santo Domingo y los Duques de Alba sustentan a la institución dominica representada por sus ejemplares hijos. Esta concepción paternalista y genealógica de los hastiales en dirección vertical ascendente se ve mucho más clara en el Árbol de la Orden de Santo Domingo que ilustra la Meditación 28 de Juan de Torquemada, modelo que se repite y que copia el conocido recurso visual del árbol de Jesé para explicar los orígenes y fundamento reforzado y explicado mediante una imagen, que Diana Lucía Gómez-Chacón cita para explicar el imaginario observante propio de la reforma y su correspondida renovación visual ${ }^{17}$. La idea del árbol que nace del santo fundador de la Orden alcanzó un profuso desarrollo, como dan cuenta ejemplos posteriores, cabe destacar el ejecutado en yeso en la rica cubierta estucada del sotocoro de la iglesia de Santo Domingo de Oaxaca, uno de los mejores exponentes del barroco hispanoamericano en donde la genealogía dominicana, en sincretismo con el árbol de la vida prehispánico, recibe a los fieles. Vemos así, cómo la idea de genealogía, paso del tiempo, origen y desarrollo, entre otras, se materializan en la plástica de distintas formas según las funciones y el mensaje.

El linaje, en un sentido amplio, entrelaza los inicios con la actualidad, bien se trate del Cardenal, las figuras ejemplares de la Orden de Santo Domingo o el propio Emperador. Las tallas de la Universidad, Hércules, Alejandro y demás personajes clásicos empleados como protagonistas del linaje imperial, se descubren en San Esteban con el mismo propósito. Hércules como antepasado se retoma de forma habitual en los siglos XV y XVI en Europa, como se observa en el Pilar y en el Palacio de Carlos V en la Alhambra de Granada. Apunta Gabaudan que la identificación de Carlos con Hércules se convirtió en un tópico del momento, ya fuera por su voluntad o la de sus seguidores, además del apropiamiento de la figura por otros miembros de la nobleza ${ }^{18}$.

Los escudos pétreos de los padres del Cardenal en la iglesia de San Esteban flanquean una serie de figuras célebres en la historia sagrada y de los santos como era costumbre y en donde también se ponen de manifiesto sus devociones. Por vía materna, fray Juan pudo heredar la devoción por la espiritualidad dominica, como deja constancia Diana Lucía al estudiar una imagen votiva de plata de san Vicente Ferrer y D. Juan de Zúñiga y Pimentel, encargada por la condesa de Plasencia, Leonor Pimentel, en agradecimiento

\footnotetext{
17 Diana Lucía Gómez-Chacón, "Arte y reforma dominicana en el siglo XV: nuevas perspectivas de estudio", Erasmo. Revista de historia Bajomedieval y Moderna, 4, (2017), pp. 96-97.

18 Paulette Gabaudan, "La iconografía de la Universidad de Salamanca: el mito imperial", Cuadernos de Arte e Iconografía, 7, 13, (1998), pp. 39-98; y Paulette Gabaudan, Un imperio mítico: los relieves del edificio de las Escuelas Mayores de la Universidad de Salamanca: estudio iconológico, (Salamanca: Ediciones Universidad de Salamanca, 2017), pp. 60-62.
} 
por la curación milagrosa de su hijo ${ }^{19}$. Esta figura y la misma vinculación de los Zúñiga y Pimentel con la Orden de Predicadores hablan de una consolidada devoción familiar por los santos dominicos. Fray Juan descendía por parte de su madre, Isabel de Zúñiga y Pimentel, de los Condes de Benavente, Pimentel y de los Almirantes de Castilla, Enríquez ${ }^{20}$. Los escudos de los padres de fray Juan se repiten en el coro de la iglesia, puestos en el lado del Evangelio, esta vez proyectados exclusivamente hacia la selecta comunidad de San Esteban y reforzando su impronta hacia la esfera privada.

La fachada como emblema parlante de la Casa de Alba se refuerza con los escudos del Cardenal de las enjutas del gran arco que protege la fachada, también en altura y que contrastan con el único escudo dominico en el hastial, puesto en el frontispicio bajo la espadaña. Se trata del stemma liliatum, que actúa como insignia colocada como escudo que campea, como desarrollan Tomás Echarte y Alberto Montaner ${ }^{21}$. Se completa con la inscripción de Refugium Nostrum, que para el P. Espinel remite a la Orden de Predicadores y a la Iglesia como refugio y recuerda que fray Juan se propuso hacer esta iglesia como muestra de su gratitud hacia Dios por haberlo encaminado a la Orden Dominica ${ }^{22}$. Esta lectura pía del propósito del Cardenal al promover las obras de San Esteban no desvía en absoluto de los verdaderos intereses familiares, religiosos y políticos. Su formación y pertenencia a la alta nobleza se insertan en una compleja atmósfera en la que el convento se veía inmersa desde la incorporación a la Congregación de la Observancia en 1486 durante el reinado de los Reyes Católicos en una dura resistencia entre el choque de intereses de los religiosos y de los monarcas. En palabras de Guillermo Nieva Ocampo, "el interés de la monarquía en las órdenes mendicantes constituidas por religiosos capaces de ejercer un poder ideológico eminente en las comunidades urbanas castellanas, y [...] la necesidad de promover modelos sociorreligiosos de conducta imitable"23 llevaron a los Reyes Católicos y posteriormente a Carlos $\mathrm{V}$ a favorecerse de su influencia. El padre del Cardenal, D. Fadrique, cumplió funciones decisivas e influyentes en la Corte de la Monarquía Católica y, a pesar de no haber apoyado a Felipe I, recibió posteriormente de Carlos $\mathrm{V}$ el Toisón de Oro y fue nombrado miembro honorífico de los Consejos de Estado y de Guerra, explicado por Rebeca

\footnotetext{
19 Diana Lucía Gómez-Chacón, "Linaje y devoción en la Plasencia del siglo XV: San Vicente Ferrer y don Juan de Zúñiga y Pimentel", Ars Longa, 25, (2016), pp. 99-113.

${ }^{20}$ Cortés Vázquez y Gabaudan, Fachada de San Esteban, p. 39.

21 Tomás Echarte y Alberto Montaner Frutos, "Los emblemas de la orden de predicadores: el Stemma Liliatum y el Stemma Formatum", Emblemata: Revista aragonesa de emblemática, 3, (1997), pp. 393394.

22 José Luis Espinel Marcos, "Simbolismo cristiano en la iglesia de San Esteban de Salamanca", Archivo Dominicano, 12, (1991), p. 407.

${ }^{23}$ Guillermo Nieva Ocampo, "La creación de la observancia regular en el convento de San Esteban de Salamanca durante el reinado de los Reyes Católicos", Cuadernos de historia de España, 80, (2006), p. 124.
} 
Sanmartín y Álvaro Bustos al reseñar la figura de Fadrique como hombre de armas y letras que se rodeó de las más selecta élite artística y política ${ }^{24}$.

\section{San Esteban reformado, la imagen del éxito}

La configuración de los espacios entre finales del siglo XV y el siglo XVII en San Esteban cambiaba drásticamente el conjunto conforme avanzaban las obras, sin dejar de constituir un llamativo e intencional compendio de imágenes con sus respectivas funciones y audiencias. Con la conclusión de la portada entre 1610 y 1623 , el elenco de la Orden de Predicadores elegido para el hastial terminó por conformarse por un amplio abanico de figuras locales e internacionales que perpetuaron el alcance y poder dominico.

La participación de numerosos frailes de San Esteban en la Guerra de las Comunidades quedó fijada en el documento que nace tras la convocatoria a Cortes de Carlos $\mathrm{V}$. Junto con agustinos y franciscanos, defendieron oponerse a la política real y apoyar a la causa comunera en contra de los intereses y abusos del recién llegado mandatario. Con la victoria de Carlos $\mathrm{V}$, el Maestro General Fr. García de Loaysa, a partir de julio de 1521, fue el encargado de efectuar las respectivas sanciones de tal forma que la Orden no perdiera el apoyo real ni su posición en el bando imperial, como explica Nieva Ocampo ${ }^{25}$. La inicial resistencia de San Esteban a incorporarse a la Reforma se debió a varios factores, para el P. Vicente Beltrán de Heredia no solo se justificó por el modo violento con el que se quería imponer la Congregación de la Observancia, sino por la tradicional competencia del convento salmantino con el de San Pablo de Valladolid, en donde se había gestado la dicha Congregación. ${ }^{26}$ La respuesta a la situación generada por los bandos que tomaron los frailes en Salamanca respecto a la Reforma y a la monarquía, tras la victoria del proceso reformador y de Carlos V, se materializó visualmente como imagen del éxito y de apoyo de San Esteban en la fachada de su iglesia. La estrecha relación de Fadrique con el bando reformado y de su hijo como vínculo con el convento explican las decisiones tomadas para trazar el proyecto del nuevo conjunto. Fray Juan intensificó el mensaje triunfal en la nueva iglesia, en donde no solo se liga a la figura imperial a través de la labor de su familia en las funciones políticas, sino incidiendo en los mismos recursos visuales de la victoria en la España de Carlos V. El mismo Cardenal acompañó en septiembre de 1535 al convento de San Esteban al Maestro de la Orden, Fr. Juan Fenario, y le informó de la situación del convento de admitir a conversos y de los problemas que con llevaba, por lo

\footnotetext{
24 Álvaro Bustos Táuler y Rebeca Sanmartín Bastida, "Fadrique Álvarez de Toledo, II Duque de Alba y su inventario de libros (1531): una biblioteca patrimonial", Revista General de Información y Documentación, 26, 1, (2016), pp. 274-276.

${ }^{25}$ Guillermo Nieva Ocampo, "Frailes revoltosos: corrección y disciplinamiento social de los Dominicos de Castilla en la primera mitad del siglo XVI", Hispania. Revista Española de Historia, 71, 237, (2011), pp. 50-51.

26 Vicente Beltrán de Heredia, Historia de la reforma de la provincia de España (1450-1550), (Roma: Institutum Historicum FF. Praedicatorum, 1939), pp. 20-24.
} 


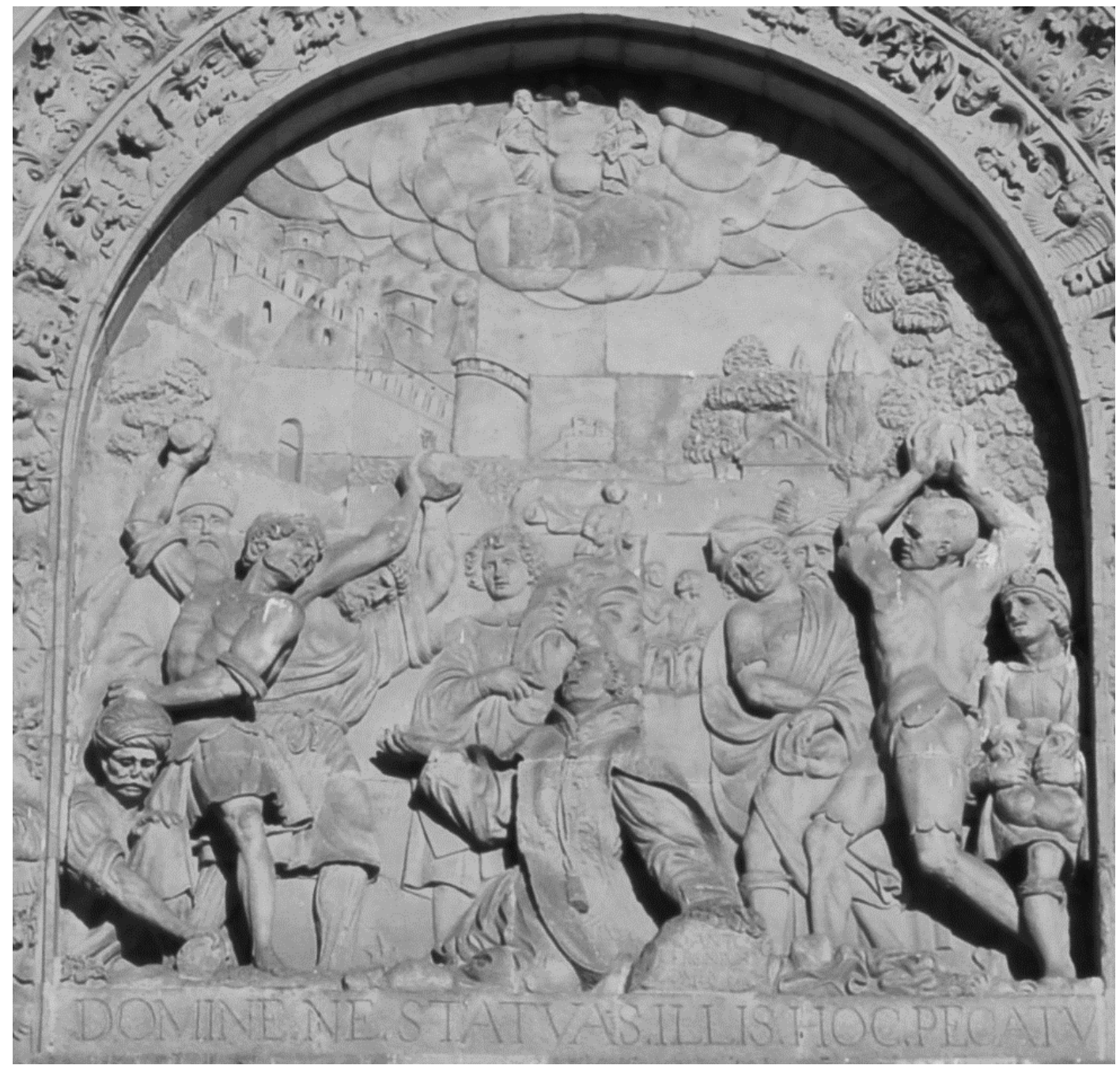

Fig. 5. Juan Antonio Ceroni, Martirio de San Esteban, 1610. Detalle de la fachada de la iglesia de San Esteban. Salamanca (Foto Santiago Abella $\odot$ )

que el Maestro determinó prohibir la profesión y estancia de aquellos hermanos descendientes de judíos en San Esteban ${ }^{27}$. La limpieza de sangre les avalaba su posición como faro de la Cristiandad bajo la dirección dominica, que también se publicitaba con los medallones del primer friso de la fachada, en donde Santiago y san Jorge destacan por sus esfuerzos en contra de la herejía y el rey David como base del Mesías y ejemplo de rey y buen gobernante en el mismo renglón en el que se disponen las armas y alusiones del Cardenal y sus padres. Nieva Ocampo concluye que:

"la decisión adoptada por los vicarios de la reforma de vincular el éxito de la congregación -sumamente resistida por los conventos de las provincias- al apoyo de la Corona significó la integración creciente de los conventos dominicos en el aparato político de la monarquía. [...]

27 Nieva Ocampo, "Frailes revoltosos...", p. 60. 
Finalmente, la derrota de los comuneros se tradujo en un agravamiento del proceso de disciplinamiento social, con el castigo de los frailes a favor de los rebeldes y con una serie de medidas correctivas que terminaron por acallar la insubordinación e imponer la docilidad. El crecimiento que experimentaron las comunidades dominicas a partir de 1525 así como la imposición, para nada conflictiva, de los estatutos de limpieza de sangre en los centros de formación de la Orden desde 1535 manifiestan el grado de integración y de permeabilidad de los frailes al proceso de confesionalización iniciado en tiempos de Carlos I. Situación que los convertiría en personajes idóneos para colaborar activamente en la construcción de la Monarquía Católica de Felipe II"28.

La investigación de Sonia Caballero sobre la campaña de difamación emprendida desde el convento de Santo Tomás de Ávila por Fr. Tomás en Torquemada ya apuntaba un contundente impulso de la Orden en contra de los judíos con un programa de propaganda inquisitorial en el que Torquemada se valió de la manipulación de imágenes para asentar la idea del apoyo regio ${ }^{29}$. En el caso de San Esteban no sería difícil construir otro orden de imágenes que resaltaran las virtudes de los Predicadores en contra de la herejía, sobre todo con las nuevas directrices del convento y de la expuesta limpieza de sangre de sus integrantes. Los santos del cuerpo central que no pertenecen al grupo de dominicos completaban el teatro devocional y que, como dedujeron Ceballos y Gabaudan, estarían ligados al patronato del promotor, su familia y el prior que contrató a Juan Antonio Ceroni para las estatuas $^{30}$.

Algunas esculturas merecen especial atención. La historia principal en donde se representa el martirio de san Esteban como titular del templo se ubica en el cuerpo central de la fachada, de la que Julián Álvarez Villar dice que "responde al concepto de iconografía que se deseaba representar, al ser de clara comprensión por quien la contempla, contando con la tradición interpretativa popular de las historias de los santos"31, y así es, la representación tal como se ve no dejaba lugar a dudas entonces, el titular ocupa el espacio más importante, al igual que en el altar elaborado a finales del siglo XVII por José Benito de Churriguera para la capilla mayor de la iglesia en el que luce la pintura del martirio de Claudio Coello entre las esculturas de san Francisco de Asís y de santo Domingo de Guzmán en las calles laterales del primer cuerpo. La imagen del Protomártir como diácono lapidado ya había circulado entre las bibliotecas académicas y se encontraba en la cultura visual de los lectores y estudiosos de los textos de teología. Se constata en el siglo XVI con el establecimiento de la imprenta del convento

${ }^{28}$ Ídem, p. 63.

29 Sonia Caballero Escamilla, Las imágenes de evangelización y condena: Torquemada y el Convento de Santo Tomás de Ávila, (Madrid: Fundación Universitaria Española, 2014).

30 Rodríguez G. de Ceballos, Iglesia y el convento, p. 128; Cortés Vázquez y Gabaudan, Fachada de San, p. 107.

31 Julián Álvarez Villar, Los conventos de San Esteban y las Dueñas, (Salamanca: Gruposa S.A., 1998), p. 18. 
de San Esteban gracias a los esfuerzos de Fr. Domingo Báñez, que encargó al impresor francés Antonio Renaut la confección de un grabado de san Esteban en su martirio y que, como ha estudiado Lázaro Sastre, "se convertirá en los siglos XVI y XVII en el emblema más usado, pero no exclusivo, de la imprenta dominicana de Salamanca"32. En la portada del comentario de De Fide, Spe \& Charitate ${ }^{33}$, impresa en 1584, en donde la imagen se acompaña de dos escudos de la Orden y dos perros con antorcha en las esquinas, sobre la estampa, aparece la inscripción con el pasaje bíblico que explica la escena, al igual que en la fachada, DOMINE NE STATUAS ILLIS HOC PECCATUM. Y bajo ella se lee SAPIENTIAM NON VINCIT MALITIA. Esta segunda parte marca las tintas en el carácter docto de los religiosos de Santo Domingo, pues se pondera la sabiduría como escudo impenetrable ante la maldad o el vicio, y resulta cuanto menos elocuente para el libro en el que se encuentra. La idea de sello o emblema figurativo de una institución o conjunto va más allá de lo que se la actualidad se podría pensar, como ha estudiado Lucía Lahoz para el sello de la Universidad de Salamanca, que disuelve las barreras geográficas y funciona como presencia y respaldo de la institución que representa ${ }^{34}$.

La estampa del convento de San Esteban se fija en el siglo XVI para representar su labor editorial, y termina por encontrarse inmersa en el imaginario colectivo de los que habían consultado las conocidas obras de los teólogos impresas en San Esteban, además de cristalizar como representación del convento en los comunicados oficiales y otra documentación. Con el paso del tiempo la imagen se repitió sin el texto complementario, como se ve en otra publicación de $1636^{35}$. Vuelve a llamar la atención la intervisualidad, esta vez no solo establecida entre exterior e interior, sino hacia cualquier parte a donde llegaran los volúmenes salmantinos. Esta ruptura total de fronteras difundió la imagen del convento condensada en su titular. La disposición del Protomártir en la talla de Ceroni en la fachada tiene como precedente la estampa de Renaut. El escultor italiano parte de la iconografía tradicional y adapta el pasaje a los gustos del momento al exacerbar la expresividad de la figura y la composición abigarrada y dramática que consigue con los personajes que lo están apedreando, sin perder de vista su vestimenta como diácono y el fondo (Fig. 5). Los medallones de Job, Salomón y Abraham e Isaac traducen los puntos fuertes de los frailes reformados y ejemplares de San Esteban, dotados de paciencia, sabiduría y $\mathrm{fe}^{36}$. Estas tres imágenes que se encuentran sobre la historia central del martirio de san Esteban, al igual que veíamos en la citada

\footnotetext{
32 Lázaro Sastre Varas, "La imprenta del convento de San Esteban de Salamanca", Memoria ecclesiae, 33, (2009), p. 89.

33 Domingo Báñez, De fide, spe \& charitate, (Salamanca: Apud S. Stephanum Ordinis Praedicatorum, 1584).

${ }^{34}$ Lucía Lahoz, "La imagen de la Universidad Pontificia", Universidad de Salamanca, Actas, pp. 484-492.

35 Sastre Varas, "La imprenta del...", p. 101.

${ }^{36}$ Rojas Bustamante, "Fray Juan Álvarez...", p. 407.
} 


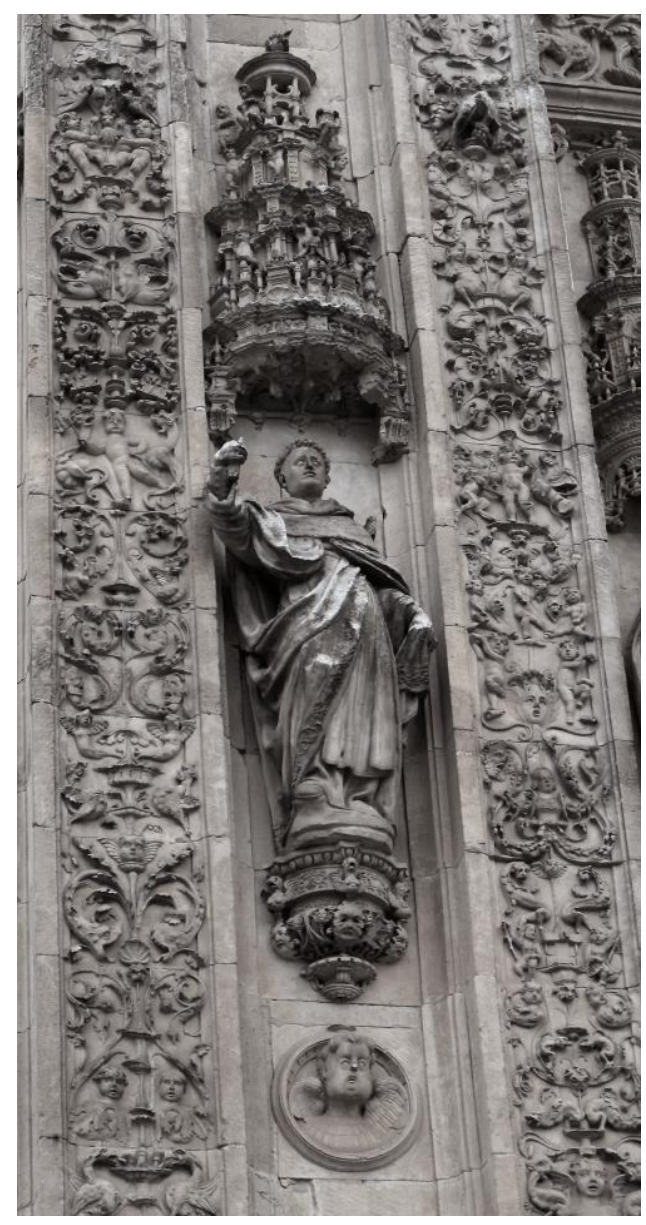

Fig. 6. Anónimo, Enrique Susón, ca.1610-1623. Detalle de la fachada de San Esteban. Salamanca. (Foto autor@)

estampa de la imprenta conventual de 1584, inciden en el lema de los Predicadores de Salamanca, victoriosos ante el vicio gracias al estudio, obediencia y oración.

Otra estatua del hastial que resulta de gran interés es la de san Antonio Abad, que se encuentra en la esquina izquierda en la parte exterior, fuera del gran arco y que descolocaba a parte de la historiografía por la elección para este conjunto. Lucía Lahoz estudia y recoge para la figura del santo ermitaño en la planta alta del edificio universitario salmantino que funcionaba como advertencia a quienes ensuciaran el lugar, y que "coincide con una costumbre registrada en refranes, como recoge Tavera, pues en un vocabulario de refranes escrito por el maestro Correas en el siglo XVII se afirma: «Pintar san Antonios en escondrijos [...] para amenazar a quien se atreviera a hacer aguas en este lugar»". Lahoz concluye que, "denuncia otros cometidos de la imagen, y delata la preocupación del Estudio por mantener un recinto 
decoroso"37. En San Esteban no hay ninguna inscripción que aclare la iconografía, pero su ubicación en la esquina exterior podría encontrarse en esta línea de mantener la limpieza y decoro del monumental entorno, sobre todo en un lugar tan transitado y visible, como dan cuenta también los vítores que se encuentran en el muro.

Otro llamativo personaje que precede el conjunto es el beato Enrique Susón (Fig. 6). Se proyecta en dirección ascendente y decidida mientras sujeta con su mano derecha una cruz, que no ha llegado a la actualidad. Esta iconografía se elige para transmitir su ideología platónica, ubicándolo en un lugar privilegiado en el machón frontal izquierdo y en pareja con san Alberto Magno en el derecho, que lo impulsó a ingresar en la Orden. A la luz de los textos de Susón y de una ilustración en el manuscrito más antiguo de Exemplar ( $h$. 1370) que aparece en el f. 82r del Ms. 2929 de la Biblioteca Nacional Universitaria de Estrasburgo, estudiado y explicado por Silvia Bara ${ }^{38}$, se entiende la idea sobre el camino de regreso del individuo a la esencia divina. Se puede observar cómo en San Esteban la disposición del Beato resalta su carácter místico, como en el citado manuscrito en el que se completa con la inscripción "iOh!, mira cómo debo morir y ser crucificado como Cristo", por lo que la imagen funcionaría como auténtica lección pétrea de su filosofía.

La escultura de san Antonino de Florencia (Fig. 7) en la esquina izquierda del segundo cuerpo y en simetría con san Vicente Ferrer tampoco pasa desapercibida. Para Ezra Sullivan, Antonino Pierozzi jugó un papel fundamental en la Reforma de la Orden en el territorio italiano y fue visto como ideal de predicador, seguidor de santo Tomás de Aquino y ejemplar obispo católico. Su figura revela el peso de la tradición medieval dominica en la cultura florentina que vio nacer el Renacimiento, influyendo en personalidades como Marsilio Ficino y fray Girolamo Savonarola ${ }^{39}$. A través de los textos de este último y los de santa Catalina de Siena, los dominicos reformistas de la Provincia de España entre 1461 y 1513 se inspiraron con las ideas de unidad y espiritualidad, como desarrolla Sastre ${ }^{40}$. Gregorio Magno, en el cuerpo superior, destaca por la sabiduría y determinación al reformar la liturgia, en simetría con León Magno que incide en la astucia política y de gestión que debe poseer una autoridad eclesiástica. Los acompañan los santos Pablo y Pedro como imagen pontificia y en vinculación directa con la biografía que Constantino de Orvieto escribió sobre santo Domingo, según la cual se aparecieron ante el santo de Caleruega para dar-

\footnotetext{
37 Lucía Lahoz, "Imagen visual de la Universidad de Salamanca" en Historia de la Universidad de Salamanca, Volumen IV: Vestigios y entramados, coord. Luis Enrique Rodríguez San-Pedro Bezares y Juan Luis Polo Rodríguez, (Salamanca: Ediciones Universidad de Salamanca, 2009), pp. 318-319.

38 Silvia Bara Bancel, "El misterio humano al encuentro con Dios: antropología del Beato Enrique Susón", Ciencia Tomista, 130, 423, (2003), p. 163.

${ }^{39}$ Ezra Sullivan, "Antonino Pierozzi: A Locus of Dominican Influence in Late Medieval and Early Reinassance Florence", Angelicum, 93, (2016), p. 358.

${ }^{40}$ Lázaro Sastre Varas, "Encanto de lo toscano. Traducciones de dominicos españoles de la espiritualidad de dominicos toscanos", en Los dominicos españoles e iberoamericanos y la traducción, ed. Antonio Bueno García, (Granada: Comares, 2018), pp. 171-193.
} 


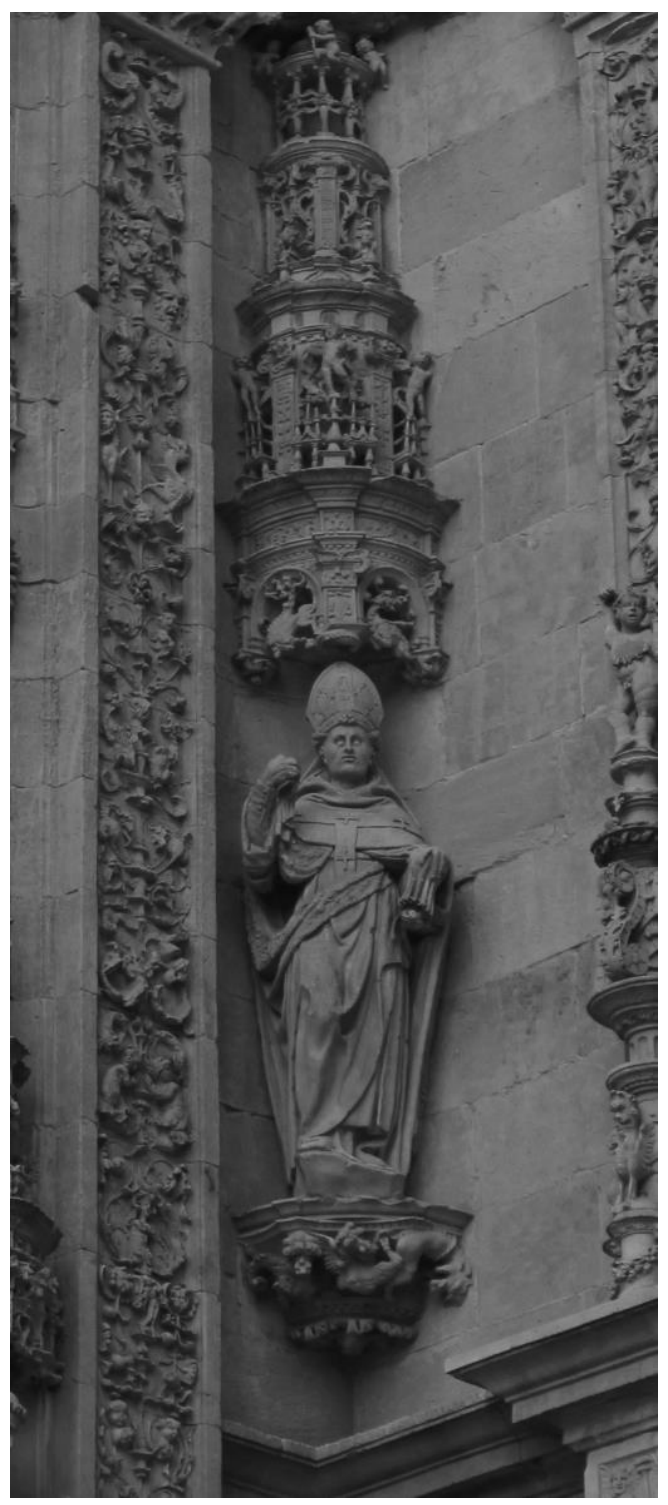

Fig. 7. Anónimo, San Antonino de Florencia, ca.1610-1623. Detalle de la fachada de la iglesia de San Esteban. Salamanca (Foto autor@)

le el báculo y el libro de la ciencia sagrada para emprender la misión apostólica de la predicación.

Así, las estatuas de la fachada giran en la órbita de la defensa de los principios dominicos, que se reformaron sin caer en la disgregación de la Orden. Los dominicos se agrupan según sus capacidades: intelecto, liderazgo, predicación, devoción y fundadores. Gonzalo de Amarante, Pedro González Telmo, Gil de Santarem y Luis Beltrán en el machón izquierdo engloban el concepto del viaje del predicador, como ejemplo de misionero y a la vez como protectores de aquellos que partían a evangelizar. San Telmo estaba vinculado al entorno castellano y servía como ejemplo de retórico, venerado por la comunidad de San Esteban. En el machón derecho, Inés de 
Montepulciano y Raimundo de Peñafort destacan por sus capacidades de liderazgo y de firmeza en la dirección de sus comunidades. Las figuras de los santos Antonino, Tomás de Aquino, Pedro Mártir y Vicente Ferrer en el segundo cuerpo se ubican sobre santo Domingo, san Jacinto de Polonia, santa Catalina de Siena y san Francisco de Asís en el primer cuerpo como arquetipos y pioneros de la recuperación del espíritu mendicante. El cristalizado elenco dominico fue pintado en 1672 en el cancel de madera ubicado entre la puerta de entrada a la iglesia y la contraportada a los pies del templo, en donde aparecen representados como ángeles, todos identificados por sus símbolos y con cartelas. Este pequeño espacio reforzaba y resumía sintética y claramente el grupo de herederos y seguidores de la labor apostólica de Domingo. El público en general se metía en contexto y recorría a modo de monumental película las historias bíblicas y religiosas a través de la entrada, iglesia y claustro. Tal cantidad de información no podía desaprovecharse, y de esa forma se construyó el gran relato legitimador del poder institucional de la Orden, secundada por el apoyo monárquico y eclesiástico.

\section{Consideraciones finales}

La conflictiva situación tras la Guerra de las Comunidades y la Reforma dominica, como se ha expuesto, tuvo como respuesta el megalómano proyecto de la fachada de San Esteban, en el que convergen los discursos de la victoria de los Dominicos con la de la nobleza del bando de Carlos V, por lo que no solo se liga el promotor y su familia a la protección divina, sino a la regia. A modo de apoteosis del poder dominico en Salamanca, la configuración icónica del conjunto entre los siglos XV y XVII presenta su inclusión en la historia sagrada y mítica, en la que coexisten figuras bíblicas, beatos, santos y religiosos ejemplares, con el discurso clásico a partir de Hércules y la Antigüedad Clásica evocada con los medallones y personajes clásicos. La figura del Emperador se posiciona como referencia obligada para el resto de las élites del momento, no es casualidad que sus allegados repitan sus estrategias visuales de distinción, pues el código era asimilado por la sociedad como imagen de poder, bien religioso, bien civil. La vinculación entre el Rey y la nobleza se manifiesta en las imágenes del templo dominico de Salamanca.

El relato principal que articulan Cristo y sus predicadores se complementa con las imágenes alusivas al linaje del promotor. Así, la fachada se tiene como la petrificación del ideario bajomedieval presentado en estilo renacentista, que no solo explica el imaginario del siglo XVI en España, sino que funciona como gran marquesina o resumen del recorrido visual del que el público participaría en distintos niveles, bien en la liturgia, pedagogía o en la semblanza de los Dominicos como congregación poderosa. El estudio de la imagen, linaje y discurso de la portada oeste de la iglesia condensa la 
información del interior, jugando con la intervisualidad y el afianzamiento de las imágenes con sus respectivos usos y funciones.

La concepción del tiempo plasmada en el hastial se encuentra en la órbita de la propia decadencia humana frente a la eternidad divina. La imagen inicial del hastial estuvo en la línea de apoyo a la victoria de Carlos V, expresada en el linaje del Cardenal como nueva cara de uno de los conventos dominicos más importantes del momento. Las cuatro edades reflejadas en los rostros de las harpías del primer friso -como estudiaron Cortés y Gabaudan como un eslabón temporal entre los orígenes y una nueva etapa ${ }^{41}$ - parecen dirigirse hacia el escudo central de Fr. Juan y se encuentran en la línea de esa inmortalización proyectada en el retablo pétreo. Al igual que su padre, las figuras de Hebe y Hércules, los personajes bíblicos y los gloriosos santos, el Cardenal consigue superar la corrupción de la carne y distanciarse de su carácter mortal. Así, en este primer cuerpo la idea del tiempo estructura un complejo análisis del calendario y del discurrir de las horas sin vuelta atrás, asegurándose la salvación del alma.

Con la concreción del proyecto, la imagen exitosa de la Orden reformada terminó de hilarse. La elección de las imágenes acusa la intervisualidad establecida con los demás espacios del conjunto conventual y de otros espacios en Salamanca. Nos situamos ante la fachada como resumen o índice del esplendor que quisieron reflejar los Dominicos implicados en la construcción institucional de San Esteban como centro rector.

${ }^{41}$ Cortés Vázquez y Gabaudan, Fachada de San Esteban, p. 106. 
Bibliografía:

Álvarez Villar 1998: Julián Álvarez Villar, Los conventos de San Esteban y las Dueñas, (Salamanca: Gruposa S.A., 1998).

Arias de Saavedra Alías 2001: Inmaculada Arias de Saavedra Alías, "Las universidades hispánicas durante el reinado de Carlos V", en Carlos $V$ y la quiebra del humanismo político en Europa (1530-1558): Congreso internacional, Madrid 3-6 de julio de 2000, coord. José Martínez Millán, (Madrid: Sociedad Estatal para la Conmemoración de los Centenarios de Felipe II y Carlos V, 2001), pp. 369-406.

Báñez 1584: Domingo Báñez, De fide, spe \& charitate catholico Regi Philippo II. Magno Hispaniarum Monarchae, Scholastica Commentaria in Secundam Secundae Angelici Doctoris partem, quae ad Quaestionem Quadragesimam sextam protenduntur, dicata. Autore fratre Dominico Bañes Mondragonensi Ordinis Praedicatorum Salmantica Sacra Theologia Primario professore, (Salamanca: Apud S. Stephanum Ordinis Praedicatorum, 1584).

Bara Bancel 2003: Silvia Bara Bancel, "El misterio humano al encuentro con Dios: antropología del Beato Enrique Susón", Ciencia Tomista, 130, 423, (2003), pp. 139-188.

Beltrán de Heredia 1939: Vicente Beltrán de Heredia, Historia de la reforma de la provincia de España (1450-1550), (Roma: Institutum Historicum FF. Praedicatorum, 1939).

Biersack 2019: Martin Biersack, "El Humanismo italiano en Castilla: vías y centros de difusión en el siglo XV", en Humanistas, helenistas y hebraístas en la Europa de Carlos V, coord. Miguel Anxo Pena González e Inmaculada Delgado Jara, (Salamanca: Universidad Pontificia de Salamanca, 2019), pp. 25-58.

Bustos y Sanmartín 2016: Álvaro Bustos Táuler y Rebeca Sanmartín Bastida, "Fadrique Álvarez de Toledo, II Duque de Alba y su inventario de libros (1531): una biblioteca patrimonial", Revista General de Información y Documentación, 26, 1, (2016), pp. 273-290.

Caballero Escamilla 2014: Sonia Caballero Escamilla, Las imágenes de evangelización y condena: Torquemada y el Convento de Santo Tomás de Ávila, (Madrid: Fundación Universitaria Española, 2014).

Camille 2005: Michael Camille, Arte gótico. Visiones gloriosas, (Madrid: Akal, 2005).

Checa Cremades 1987: Fernando Checa Cremades, Carlos V y la imagen del héroe en el Renacimiento, (Madrid: Taurus, 1987). 
Cortés Vázquez y Gabaudan 1995: Luis Cortés Vázquez y Paulette Gabaudan, La fachada de San Esteban, (Salamanca: Ediciones de la Diputación de Salamanca, 1995).

Cuervo 1914: Justo Cuervo, Historiadores del Convento de San Esteban de Salamanca, (Salamanca: Imprenta católica salmanticense, 1914).

Echarte y Montaner 1997: Tomás Echarte y Alberto Montaner Frutos, "Los emblemas de la orden de predicadores: el Stemma Liliatum y el Stemma Formatum", Emblemata: Revista aragonesa de emblemática, 3, (1997), pp. 393-434.

Espinel Marcos 1978: José Luis Espinel Marcos, San Esteban de Salamanca. Historia y guía, siglos XIII-XX, (Salamanca: Editorial San Esteban, 1978).

Espinel Marcos 1991: José Luis Espinel Marcos, "Simbolismo cristiano en la iglesia de San Esteban de Salamanca", Archivo Dominicano, 12, (1991), pp. 386-415.

Gabaudan 1998: Paulette Gabaudan, "La iconografía de la Universidad de Salamanca: el mito imperial", Cuadernos de Arte e Iconografía, 7, 13, (1998), pp. 39-98.

Gabaudan 2017: Paulette Gabaudan, Un imperio mítico: los relieves del edificio de las Escuelas Mayores de la Universidad de Salamanca: estudio iconológico, (Salamanca: Ediciones Universidad de Salamanca, 2017).

Gómez Moreno 1967: Manuel Gómez Moreno, Catálogo monumental de España. Provincia de Salamanca, (Madrid: Ministerio de Educación y Ciencia, Dirección General de Bellas Artes, Servicio Nacional de Información Artística, 1967).

Lahoz 2009: Lucía Lahoz, "Imagen visual de la Universidad de Salamanca" en Historia de la Universidad de Salamanca, Volumen IV: Vestigios y entramados, coord. Luis Enrique Rodríguez San-Pedro Bezares y Juan Luis Polo Rodríguez, (Salamanca: Ediciones Universidad de Salamanca, 2009), pp. 287-325.

Lahoz 2014: Lucía Lahoz, "La imagen de la Universidad Pontificia", en La Universidad de Salamanca y el pontificado en la Edad Media, coord. Miguel Anxo Pena González y Luis Enrique Rodríguez-San Pedro Bezares, (Salamanca: Universidad Pontificia de Salamanca, 2014), pp. 483-532.

Gómez-Chacón 2016: Diana Lucía Gómez-Chacón, "Linaje y devoción en la Plasencia del siglo XV: San Vicente Ferrer y don Juan de Zúñiga y Pimentel", Ars Longa, 25, (2016), pp. 99-113.

Gómez-Chacón 2017: Diana Lucía Gómez-Chacón, "Arte y reforma dominicana en el siglo XV: nuevas perspectivas de estudio", Erasmo. Revista de historia Bajomedieval y Moderna, 4, (2017), pp. 87-106. 
Marías 1992: Fernando Marías, El siglo XVI: Gótico y Renacimiento, (Madrid: Sílex, 1992).

Nieva Ocampo 2006: Guillermo Nieva Ocampo, "La creación de la observancia regular en el convento de San Esteban de Salamanca durante el reinado de los Reyes Católicos", Cuadernos de historia de España, 80, (2006), pp. 91126.

Nieva Ocampo 2011: Guillermo Nieva Ocampo, "Frailes revoltosos: corrección y disciplinamiento social de los Dominicos de Castilla en la primera mitad del siglo XVI", Hispania. Revista Española de Historia, 71, 237, (2011), pp. 3964.

Pena González 2014: Miguel Anxo Pena González, "Dominicos y Franciscanos en las universidades medievales", en La Universidad de Salamanca y el pontificado en la Edad Media, coord. Miguel Anxo Pena González y Luis Enrique Rodríguez-San Pedro Bezares, (Salamanca: Universidad Pontificia de Salamanca, 2014), pp. 109-142.

Rodríguez G. de Ceballos 1987: Alfonso Rodríguez G. de Ceballos, La iglesia y el convento de San Esteban de Salamanca. Estudio documentado de su construcción, (Salamanca: Centro de Estudios Salmantinos, 1987).

Rojas Bustamante 2019: Juan Pablo Rojas Bustamante, "Fray Juan Álvarez de Toledo y el programa humanista de la fachada de la iglesia de San Esteban de Salamanca" en Humanistas, helenistas y hebraístas en la Europa de Carlos $V$, coord. Miguel Anxo Pena González e Inmaculada Delgado Jara, (Salamanca: Servicio de Publicaciones, Universidad Pontificia de Salamanca, 2019), pp. 381-409.

Sastre Varas 2009: Lázaro Sastre Varas, "La imprenta del convento de San Esteban de Salamanca", Memoria ecclesiae, 33, (2009), pp. 83-104.

Sastre Varas 2018: Lázaro Sastre Varas, "Encanto de lo toscano. Traducciones de dominicos españoles de la espiritualidad de dominicos toscanos", en Los dominicos españoles e iberoamericanos y la traducción, ed. Antonio Bueno García, (Granada: Comares, 2018), pp. 171-193.

Sullivan 2016: Ezra Sullivan, "Antonino Pierozzi: A Locus of Dominican Influence in Late Medieval and Early Reinassance Florence", Angelicum, 93, (2016), pp. 345-358.

Valdivieso 1975: Enrique Valdivieso González, "Una planta de Juan de Álava para la iglesia de San Esteban de Salamanca", Boletín del Seminario de Estudios de Arte y Arqueología: BSAA, Tomo 40-41, (1975), pp. 221-240.

Enviado:25/03/2019

Aceptado: 17/05/2019 